\title{
RHEOLOGICAL PROPERTIES \\ OF DATE JUICE CONCENTRATE (DIBS) DURING EVAPORATION PROCESS
}

\author{
Omnia E. Salama ${ }^{1}$, Manal A. Sorour ${ }^{1}$, M. M. Mostafa ${ }^{2}$, M. A. Elnono ${ }^{2}$
}

ABSTRACT

Date concentrate was obtained under vacuum using rotary evaporator by heating the date extract (19\%) until it reaches (70\%). Samples were collected during process until the end of process The rheological properties of Date juice concentrate were studied using Brookfield Rheometer (DV III ultra) at different temperatures (30, 40, 50 and $\left.60^{\circ} \mathrm{C}\right)$, concentrations $(30,40,50$ and $60 \%)$ and shear rates $\left(9.3-93 \mathrm{~s}^{-1}\right)$. Shear rate - shear stress data indicated that all samples exhibited nonNewtonian pseudoplastic behavior.Dependence of apparent viscosity on temperature was related through the Arrhenius law. Effect of concentration on apparent viscosity was also studied and fitted well to power law.

Keywords: Rheological Properties, Date Juice Concentrate, Flow Behavior, Activation Energy

\section{INTRODUCTION}

T $\mathrm{n}$ food industry, knowledge of the physical properties of food is fundamental in analysis, the unit operations present in the food industry. The study of these food properties and their response to process conditions is necessary because they are good indicators of other properties and qualities of food. Viscosity and it's variation with concentration and temperature are very important for the food industry in general and for fruit derivatives in particular, since it's necessary for the design and the optimization of several processing operations (e.g. pumping, evaporation, filtration, ......etc) [1].

\footnotetext{
${ }^{1}$ Food Engineering and Packaging, Department, Food Technology Research Institute, Agricultural Research Center, Giza, Egypt

${ }^{2}$ Agriculture Engineering Department, Faculty of Agriculture, Ain Shams University., Egypt
} 
Rheology is the science of deformation and flow behavior of matter. The consistency of a Newtonian fluid like water, milk or clear fruit juice can be characterization by the term viscosity. Viscosity of non-Newtonian fluid however changes with changing rate of shear and hence should be characterized by more than one parameter [ 2 and 3 ].

Knowledge of viscosity is of primary importance to the fruit juice industry.Accurate viscosity data over wide temperature, pressure, and concentration regions are needed for a various research and engineering applications in any branch of the food industry. The viscosity of fluid food is an important property which has many applications in food technology such as developing food processes and processing equipment, the control of product, filters and mixers quality evaluation and an understanding of the structure of food and raw agricultural material [4 and 5].

Fluid properties of raw and processed food products affect process design, pipeline transport, and product development as well as final product characteristics and uses. Mathematical models have been used to describe the rheological behavior of different food fluids. Some of the timeindependent and time-dependent rheological models can be simple such as Newtonian, Power law and Herschel-Bulkey [6]:

$$
\begin{gathered}
\tau=\mu \gamma \\
\tau=\mathrm{K} \gamma^{\mathrm{n}} \\
\tau=\tau_{0}+\mathrm{K} \gamma^{\mathrm{n}}
\end{gathered}
$$

Where, $\tau$ is the shear stress $\mathrm{Pa} ; \gamma$; is the shear rate $1 / \mathrm{s} ; \mu$ is the Newtonian viscosity Pa.s; $\mathrm{K}$ is the consistency coefficient, $\mathrm{n}$ is the flow behavior index, $\tau_{0}$ is the yield stress $\mathrm{Pa}$ and $\mathrm{n}$ is the flow behavior index,. The three relationships have been employed over a wide range of shear rates and in a great variety of fluids foods, whereas the last model has been used to fit the rheological behavior of dispersed systems and gums solutions.

The rheological and sensory properties of pekmez (grape molasses/tahin (sesame paste) blends were studied using pekmez concentrations of $2 \%$, $4 \%$, and $6 \%$ at $30,40,50,60,65$ and $75^{\circ} \mathrm{C}$. the pekmez content and 
temperature influenced the flow behavior and consistency index values [7].

Altay; and Ak; [8] determined the rheological properties of tahin at temperatures from $20-70^{\circ} \mathrm{C}$ and shear rates in the range of $0.13-5001 / \mathrm{s}$. Temporary hysteresis loops were observed in the first cycle of the flow curve. The consistency coefficient exhibited strong temperature dependence for which the activation energy of flow was $21.6 \mathrm{~kJ} / \mathrm{mol}$. The flow behavior index of tahin tended to increase whereas the consistency coefficient tended to decrease during storage at room temperature. Tahin oil exhibited Newtonian behavior with a strong dependence of viscosity on temperature. Viscosity of reconstituted tahin suspensions was found to be dependent on particle size only at solid contents above $20 \%$.

Sorour and assous [9] studied the Date juice of Siwi dates variety at tamr stage (simi-dry) was obtained with three different methods of extraction. In the first method, date was extracted with water at $25^{\circ} \mathrm{Cfor} 2.0 \mathrm{~min}$ (T1), the second method, date residue of extraction (T1) was subjected to second extraction at $75^{\circ} \mathrm{C}$ for $15 \mathrm{~min}$. (T2) and the last method,date was extracted at $75^{\circ} \mathrm{C}$ for $15 \mathrm{~min}$. (T3)at ratio3:1 of water/date (wt/wt). Mixing of date with water was investigated using paddle impeller. The flow behavior of date juices were studied at $25^{\circ} \mathrm{C}$, for treatment (T1) and $75^{\circ} \mathrm{C}$ for treatments (T2 and T3). The speed of spindle used is 20-200 rpm. Shear stress-Shear rate data indicate that the juice behaves as nonNewtonian pesudoplastic fluid. An impeller mixer was connected with Ammeter in order to predict the power of the mixer. Prediction of the power number, blend number and pumping number as a function of Reynolds number were plotted and this enables an economic scale -up for non-Newtonian fluid. Excellent quality of date juice and minimal time were recorded for T2 and T3. Also, it is recommended to apply the 45-91 rpm for the mixer scale-up value.

The main objectives of this work are to study the rheological properties of Date juice during evaporation process and evaluate the effect of temperature on apparent viscosity of date juice concentrate. 


\section{MATERIALS AND METHODS}

\subsection{Material}

Samples of Siwi dates were obtained from Siwi Oasis, El-Wadi El-Gidid Govenorate, Egypt.

\subsection{Methods}

\subsubsection{Processing Methods}

Extract from siwi dates variety at tamr stage (semi-dry) was obtained by:

Preparing a mixture of water-date at a ratio $3: 1(\mathrm{w} / \mathrm{w})$.Extraction by mixing with paddle impeller at 20-200 RPM with heating till TSS reached the maximal level, Fig (1) as it was previously described by [10].

Date extract was filtered using white cloth then concentrated by evaporator under vacuum $(100 \mathrm{mmHg})$ until the total soluble solids exceeded $69 \%$ as previously described by [11].

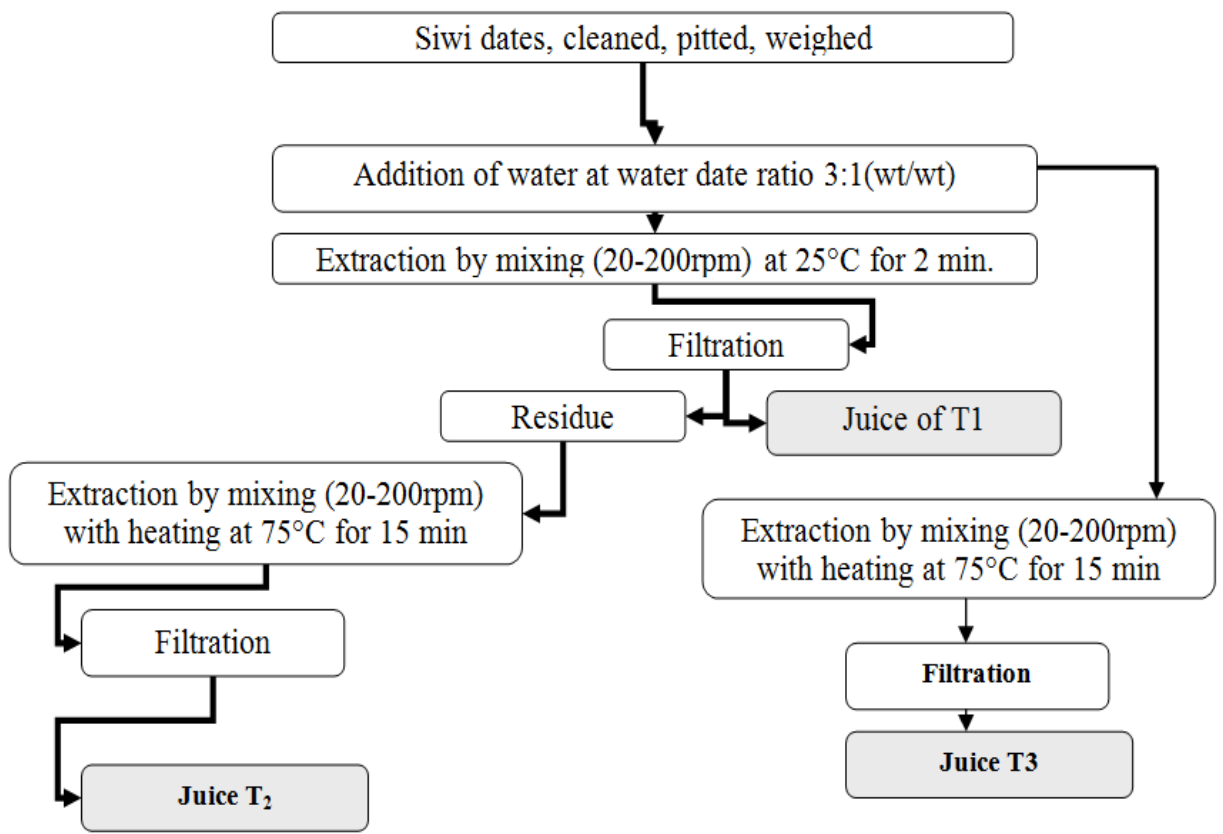

Fig. (1): Flow sheet diagram for production of date juices.

\subsubsection{Chemical Analysis of Siwi Date at Tamr Stage Date Extract, Date Juice Concentrate}

Total soluble solids (Tss, PH value, moisture content, total acidity, fiber ash, reducing, non-reducing sugars and hydroxyl fural content) were determined according to [12]. 
Pectin content was determined as described by [13].

Browning was measured (absorbance at 420nm) as mentioned in [14].

Table 1.Physical and chemical analysis of Siwi date, date extract and concentrate.

\begin{tabular}{llll}
\hline Characteristics & $\begin{array}{l}\text { Siwi } \\
\text { dates }\end{array}$ & $\begin{array}{l}\text { Siwi date } \\
\text { extract }\end{array}$ & $\begin{array}{l}\text { Date } \\
\text { concentrate } \\
\text { dibs }\end{array}$ \\
\hline $\begin{array}{l}\text { Moisture content, \% } \\
\text { TSS, \% }\end{array}$ & 17.85 & 80.41 & 29.58 \\
pH value & 76.2 & 19 & 70 \\
$\begin{array}{l}\text { Browning absorbance at (420 } \\
\text { nm) }\end{array}$ & 5.81 & 5.42 & 4.55 \\
Total sugars, \% & 0.201 & 0.268 & 0.848 \\
Reducing sugars, \% & 85.12 & 91.54 & 90.11 \\
Non-Reducing sugars, \% & 79.21 & 86.51 & 86.34 \\
Acidity as malic acid & 5.89 & 5.03 & 3.77 \\
$\begin{array}{l}\text { Pectin, \% } \\
\text { Total phenol, \% }\end{array}$ & 0.32 & 0.408 & 0.302 \\
Hydroxymethylfurfural, & 2.27 & 2.56 & 2.23 \\
mg/100gm & 0.65 & 0.714 & 0.603 \\
\hline
\end{tabular}

*on dry weight basis

\subsubsection{Rheological Properties}

Flow properties (shear rate, shear stress and apparent viscosity) of date juice and its concentrate were measured directly with Brookfield Digital Rheometer, model HA-DVIII ultra (Brookfield Engineering Laboratories INC). The concentrate was placed in a small sample adapter, SC4-21 spindle was selected for the sample measurement. A thermostatic water bath provided with the instrument was used to regulate the sample temperature. The rheological parameters for date juice concentrate were studied at different temperatures $\left(30,40,50\right.$ and $\left.60^{\circ} \mathrm{C}\right)$, shear rates 9.3$232.5 \mathrm{~s}^{-1}$ and different concentrations (30, 40, 50 and 60\%).

\section{RESULTS AND DISCUSSION}

\subsection{Rheological Properties of Date Concentrate}

The process of concentrating juices are not so easy for processors as they are faced many problems relating to the rheological properties of the 
structure of concentrate, as a result of thickening of the solid content and viscosity created.

The obtained results are illustrated in the following visions:

\subsubsection{Shear Stress - Shear Rate Relation}

Table 2. Relation between $\mathrm{k}$ and $\mathrm{n}$ with temperature.

\begin{tabular}{llll}
\hline Conc., $\%$ & Temperature, $^{\circ} \mathbf{C}$ & $\mathbf{k}$ & $\mathbf{n}$ \\
\hline \multirow{4}{*}{$30 \%$} & 30 & 0.044 & 0.661 \\
& 40 & 0.015 & 0.861 \\
& 50 & 0.064 & 0.586 \\
& 60 & 0.068 & 0.451 \\
$40 \%$ & 30 & 0.057 & 0.718 \\
& 40 & 0.015 & 1.045 \\
& 50 & 0.108 & 0.502 \\
& 60 & 0.018 & 0.838 \\
$50 \%$ & 30 & 0.051 & 0.928 \\
& 40 & 0.072 & 0.786 \\
& 50 & 0.128 & 0.619 \\
$60 \%$ & 60 & 0.023 & 0.939 \\
& 30 & 2.253 & 0.738 \\
& 40 & 1.242 & 0.75 \\
& 50 & 1.168 & 0.756 \\
\hline
\end{tabular}

Shear rate -Shear stress data of date juice concentrate $(60 \%)$ were obtained in the range of shear rates $9.3-93.00 \mathrm{~s}^{-1}$ and temperatures (30$60^{\circ} \mathrm{C}$ ). the results observed that all samples behaved as Non-newtonian pseudoplastic fluids and power law model equation (4) was fitted to experimental data. The same trend was observed at $45,55 \%$ total soluble solids of date concentrate.

$$
\tau=\mathrm{K} \gamma^{\mathrm{n}}
$$


Where, $\tau$ is the shear stress, Pa; $\mathrm{k}$ is the consistency index; $\gamma$ is the shear rate, $1 / \mathrm{s}$; and $\mathrm{n}$ is the flow behavior index.

\subsubsection{Effect of Concentration on Viscosity}

The effect of concentration on the apparent viscosity of date juice concentration at shear rate between $9.3-93.00 \mathrm{~s}^{-1}$ were investigated over a temperature rang 30-60oc, as shown in Fig (4). The results show that the change in viscosity with concentration follows the power law relationship as concentration of the extract increases the apparent viscosity increases all samples exhibited the same trend equation (6), which was mentioned by work of [15] on peach dietary fibre suspension, the authors described the variation of viscosity with concentration of peach dietary fibre.

$$
\mu=\mathrm{AC}^{\alpha}
$$

$\mu$ is the viscosity, pa.s;

$\mathrm{C}$ is the concentration, wt $\%$; and

A, $\alpha$ are empirical constant related to shear rate and temperature.

The values of flow behavior index (n) and consistency index (k) at different temperatures and concentrations are shown in Table(2).

The results show that the values of consistency index (k) and flow behavior index show a good trend with temperature at each level of concentration.

\subsubsection{Effect of Shear Rate on Apparent Viscosity}

Values of viscosity for date juice concentrate were plotted against shear rate $(\gamma)$ at different solid concentrations (30, 40, 50 and 60\% wt) and different temperatures $(30,40,50,60 \mathrm{C})$ as shown in fig. (3).

It was observed that apparent viscosity $(\mu)$ decreases with increasing shear rate, the results were fitted well to the following equation

$$
\mu=K \gamma^{\mathrm{n}}
$$

Where $\mu$ is the apparent viscosity, Pa.s;

$\gamma$ is the shear rate, $1 / \mathrm{s}$;

$\mathrm{K}$ is the plastic viscosity; and

$\mathrm{N}$ is the flow behavior index. 


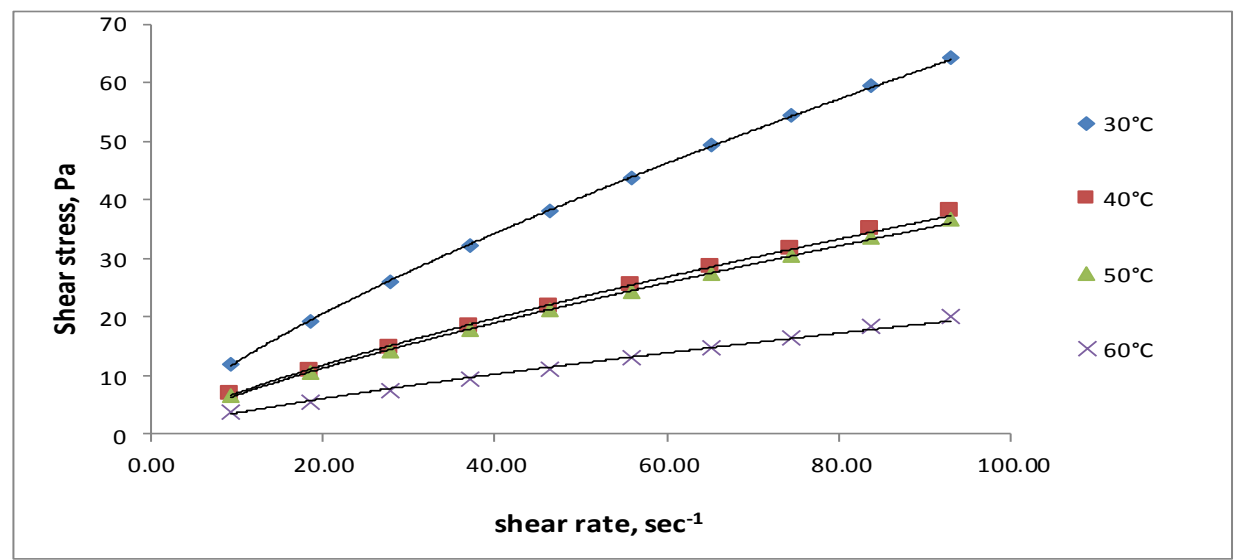

Fig. (2):Relation between Shear rate and shear stress at different temperatures and $60 \mathrm{wt} \%$ of date juice puree.

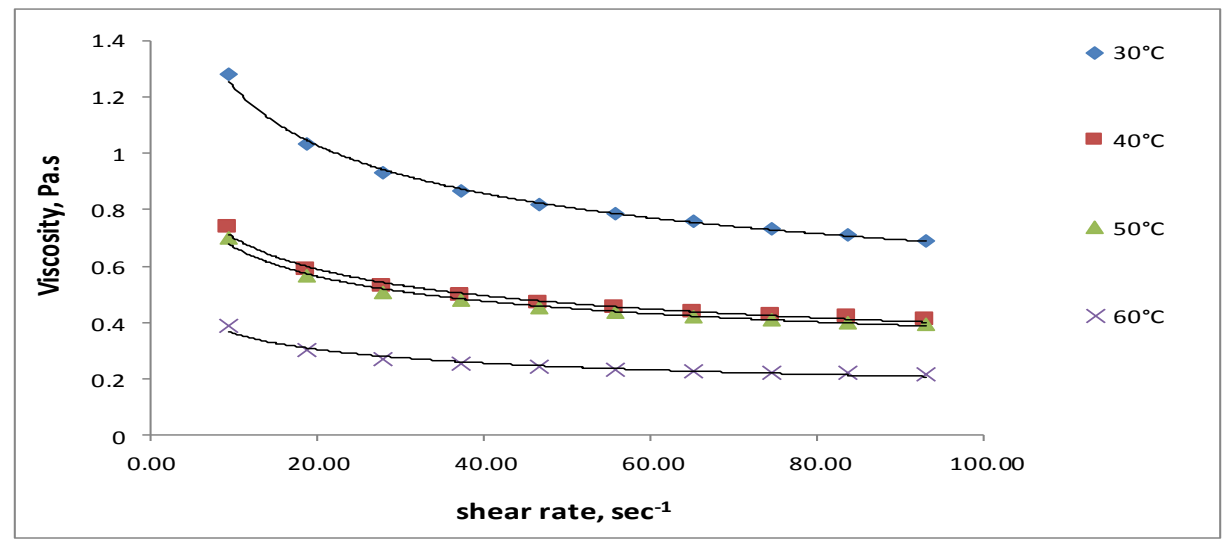

Fig.(3):Effect of shear rate on viscosity at $60 \%$ soli concentration of Date juice concentrate and different temperatures.

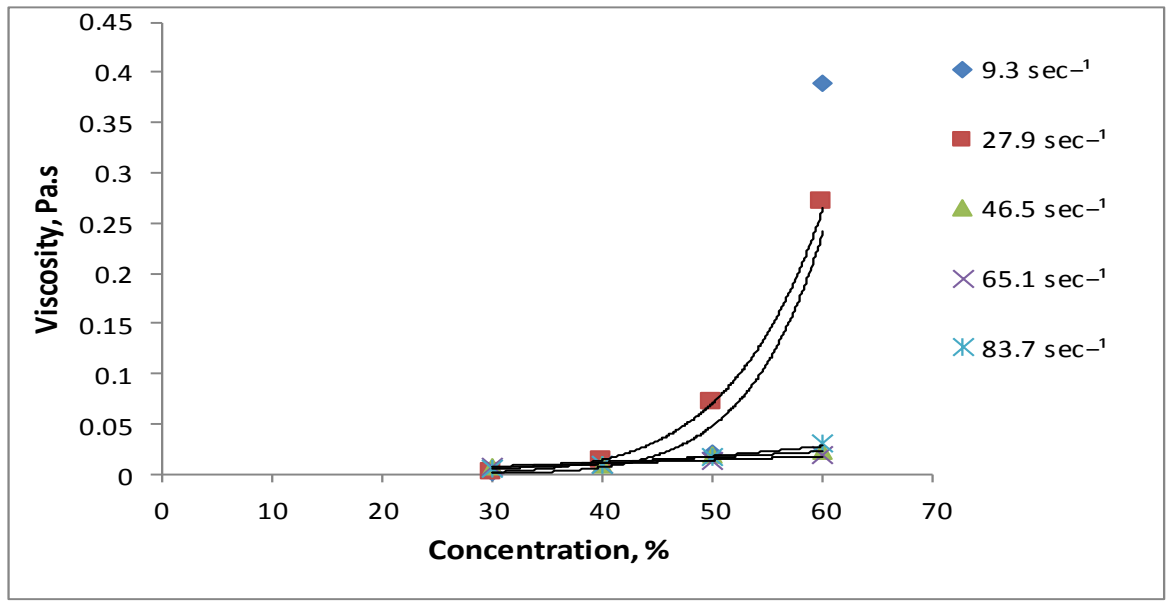

Fig.(4): Effect of concentration on viscosity at different shear rates, at $60^{\circ} \mathrm{C}$. 


\subsubsection{Effect of Temperature on the Apparent Viscosity of Date Juice}

\section{Concentrate}

Figs (5 through 7) show the variation of apparent viscosity with temperature $\left(30,40,50\right.$ and $\left.60^{\circ} \mathrm{C}\right)$ at different shear rates $9.3-93.00 \mathrm{~s}^{-1}$ and different concentration $(30,40,50,60 \%)$.

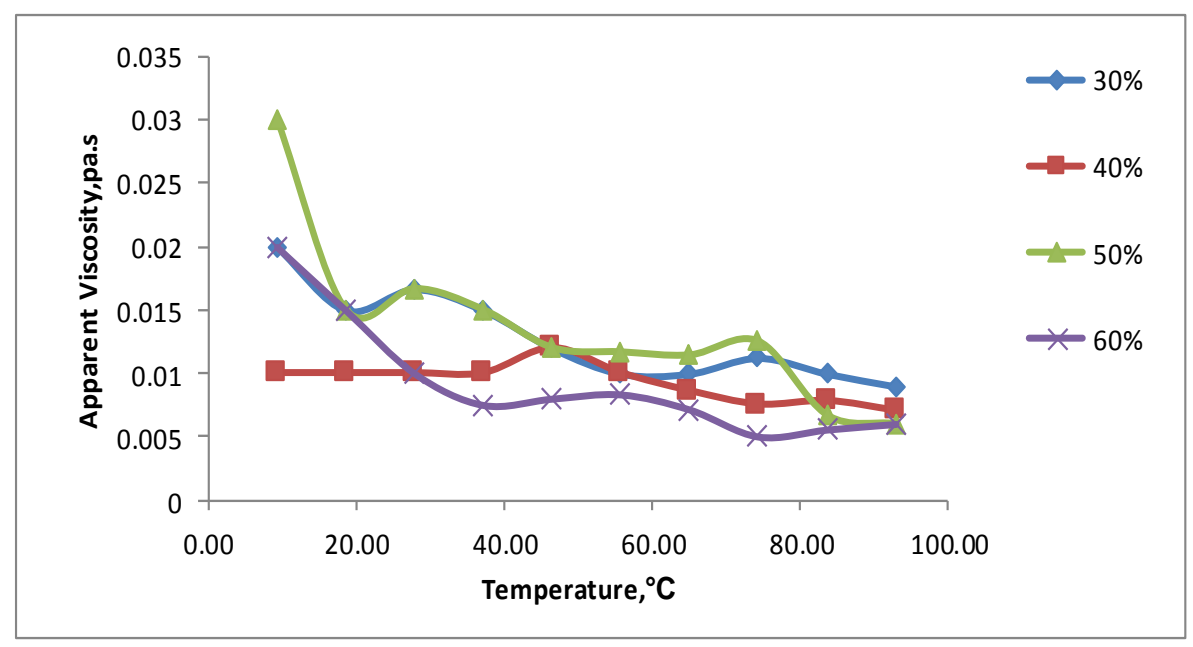

Fig.(5): Relation between viscosity and temperature at different solid concentrations of date juice concentrate.

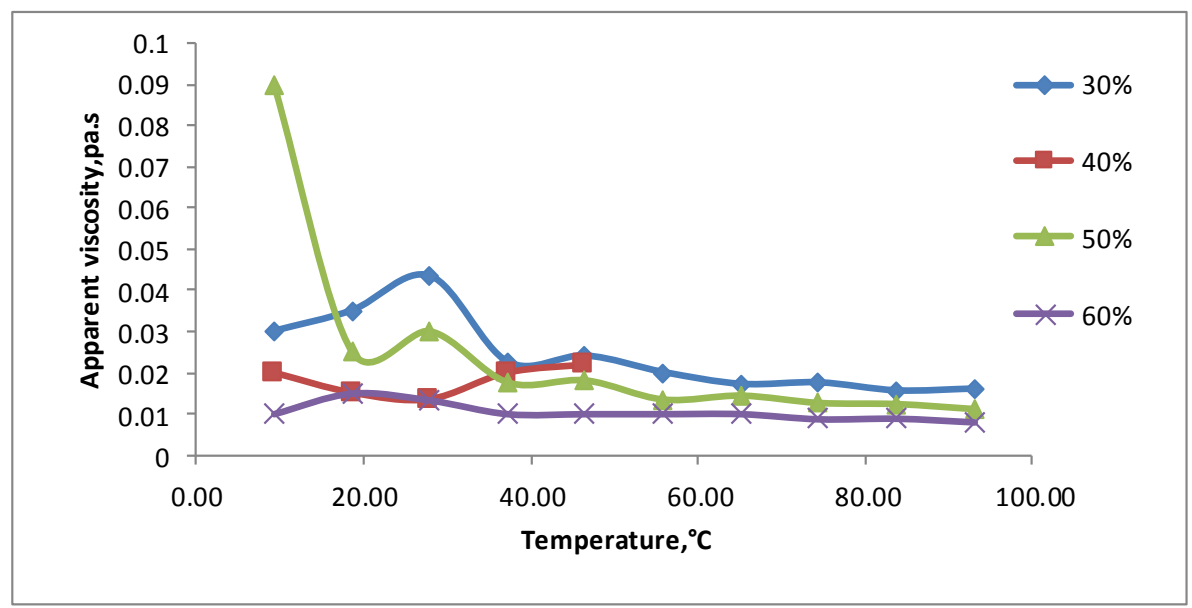

Fig.(6): Relation between viscosity and temperature at different solid concentrations of date juice concentrate 


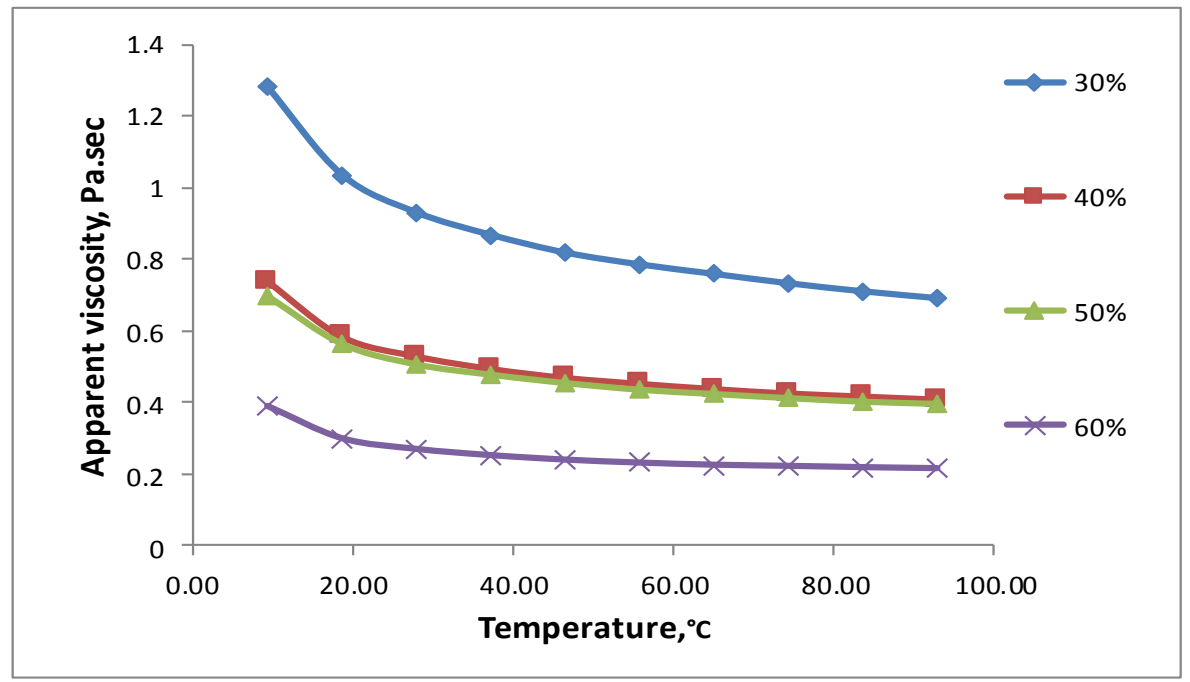

Fig.(7):Relation between viscosity and temperature at $60 \%$ solid concentration of date juice concentrate and different shear rates.

The result show that viscosity decreases with increasing temperature at all shear rates studied. The fluctuations in viscosity over a certain range of temperature may be explained due to local agglomeration of dispersed particles around the spindle which may lead to a fictitious increase in viscosity.

Figs (5 through 7) show that as temperature increases, viscosity will decreases except for concentration ( $30,40,50,60 \%$ ) as there were some fluctuations in the temperature range of 30 and $60^{\circ} \mathrm{C}$, it may be due to the effect of temperature on the structure of date juice concentrates as it contains pectin as previously discussed by [15].

The variation in apparent viscosity with temperature can be described by an Arrhenius-type equation (7):

$$
\mu=\mu \mathrm{a} \exp (\mathrm{Ea} / \mathrm{RT})
$$

Where $\mu$ is the apparent viscosity, Pa.s; $\mu \mathrm{a}$ is the constant; Ea is the activation energy of flow; $(\mathrm{kj} / \mathrm{mol}), \mathrm{R}$ is the gas constant $(8.314$ $\mathrm{kj} / \mathrm{mol} . \mathrm{K})$; and $\mathrm{T}$ is the absolute temperature in $(\mathrm{K})$. 
To obtained the estimates of the parameters of the Arrhenius relationship, the logarithm of the viscosity was plotted against $1 / \mathrm{T}$.

$$
\operatorname{Ln} \mu=\ln \mu \mathrm{a}+(\mathrm{Ea} / \mathrm{RT})
$$

Table (3) show the effect of temperature on apparent viscosity of date juice concentrate according to the Arrhenius equation and the best fit lines are drawn at $60 \%$ solid concentration of date juice concentrate, the same trend was observed at concentration 30,40, 50, and 60\% and all shear rates studied.

Table (3):Activation energy at different shear rates and concentration, $\mathrm{KJ} / \mathrm{mol}$.

\begin{tabular}{lllll}
\hline $\boldsymbol{\gamma}$ & $\mathbf{3 0 \%}$ & $\mathbf{4 0 \%}$ & $\mathbf{5 0 \%}$ & $\mathbf{6 0 \%}$ \\
\hline Sec-1 & Ea & Ea & Ea & Ea \\
9.30 & 16420.15 & 30620.46 & 20261.22 & 30337.79 \\
18.60 & 14233.57 & 7786.89 & 22846.87 & 31410.29 \\
27.90 & 14349.96 & 192.97 & 21666.28 & 31451.86 \\
37.20 & 19695.87 & 23570.19 & 25025.14 & 33829.67 \\
46.50 & 11065.93 & 25648.69 & 22630.71 & 33646.76 \\
55.80 & 3122.74 & 18930.98 & 20942.97 & 31002.91 \\
65.10 & 9286.74 & 15896.37 & 19637.67 & 30753.49 \\
74.40 & 22057.04 & 18457.08 & 20294.47 & 30229.70 \\
83.70 & 16112.53 & 14882.06 & 19562.84 & 29897.14 \\
93.00 & 10941.22 & 18756.38 & 18706.5 & 29498.07 \\
\hline
\end{tabular}

\section{CONCLUSION}

The rheological properties of date juice were studied using a Brookfield viscometer at various temperature $30,40,50,60^{\circ} \mathrm{C}$ at different concentrations, $30,40,50,60 \%$ by wt; shear rates $9.3-93.00 \mathrm{~s}^{-1}$ 
The result show that the all samples exhibited non-Newtonian pseudoplastic behavior. The result show that viscosity decreases with increasing temperature at all shear rates studied.

It is recommended to study the optimization of dibs production line as an application for food industry, due to that there are no many factories that produce dibs in Egypt.

\section{REFERENCES}

(1) Ibarz, A., Pagan, J., Gutierrez, J., \& Vicente, M., (1989). "Rheological properties of clarified pear juice concentrates, J. of food Eng., Vol. 10, 57-63,.

(2) Heldman, D. R., and Singh, R. P. (1981). food process Engineering (2nd ed.). Westport, Conn: AVI Publishing Company.

(3) Rizvi, S. S. H., and Mittal, G. S. (1997). Experimental methods in food engineering. New Delhi: CBS Publisher and Distributors, pp. 35 .

(4) Alvardo, J. D., and Romero, C. H. (1989). Physical properties of fruits I-II. Density and viscosity of juices as functions of soluble solids contentand temperature. Latin American Applied Research, vol. 19, pp. 15-21.

(5) Walker, S., and Prescott, J. (2000). The influence of solution viscosity and different viscosifying agents on apple juice flavor. Journal of Sensory Studies, vol. 15, pp. 285-307.

(6) Steffe, J. F [ED.] (1996). Rheological Methods in Food Process Engineering. 2ed. Freeman Press. East Lansing, MI. USA.

(7) Alpaslan, M. and M. Hayta. (2002). Rheological and sensory properties of pekmez (grape molasses)/tahin (sesame paste) blends. Journal of Food Engineering, 54 (1): 89-93. 
(8) Altay, F. Lokumcu and M M. AK. (2005). Effects of temperature, shear rate and constituents on rheological properties of tahin (sesame paste). Journal of the Science of Food and Agriculture, 85 (1): 105-111.

(9) M.A. Sorour and M.T. Assous, (2008), "Effect of Mixing During Extraction on the Quality of Date Juice" J. of Engineering And Applied Science, Vol. 55, No.1, pp.93-108.

(10) Assous, M.T.M. and Sorour, M.A., (2014). "Effect of concentration Methods on Quality of Date", TESCE, The Transactions of the Egyptian Society of Chemical Engineers, 40(3).

(11) A.O.A.C. (2000). "Official methods of analysis of the association of official analytical chemists International". Published by the Association of Official Analytical Chemist's International. Maryland 20877-2417. USA.

(12) Lees, R. (1975). "Food analysis: Analytical and quality control methods for the food manufacturerand buyer". Laboratory handbook of methods of analysis, Lenoard Hill Book Publisher, London, England.

(13) Ranganna, S. (1977). "Manual of Analysis of fruit and vegetable products".Tata McGraw-HillPublishing Company Limited, New Delhi.

(14) Grigelmo- Miguel, et al., (1999). "Rheology of peach dietary fibre suspensions", J. of Food Eng., Vol. 39, pp 91-99.

(15) Imeson, (1992). "Thickening and gelling agents to food", Edited by A. Imeson, Research and development manager, London Blackie Academic, 132. 


\section{الملخص العربي}

\section{الخواص الريولوجية لمركز عصير البلح (دبس) أثناء عملية التبخير}

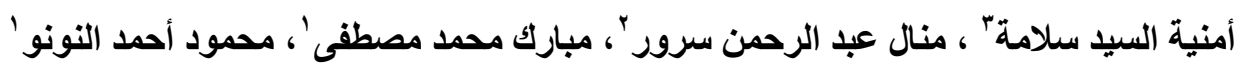

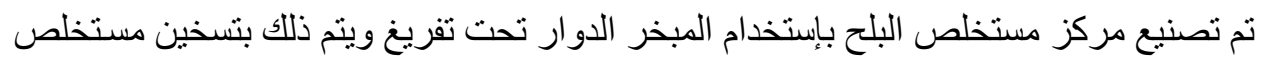

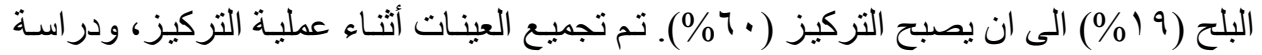

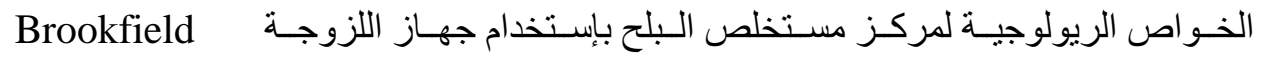
Rheometer (DV III ultra)

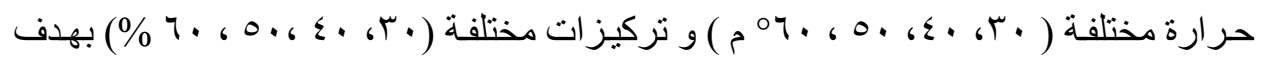

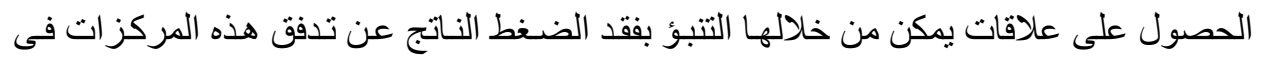

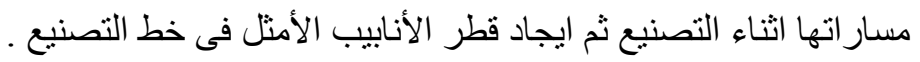

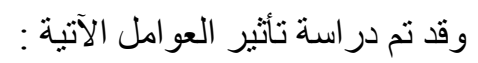

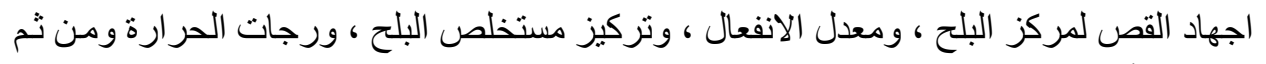

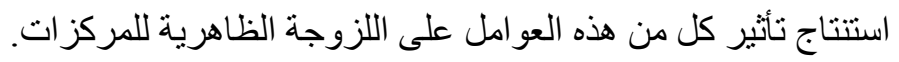

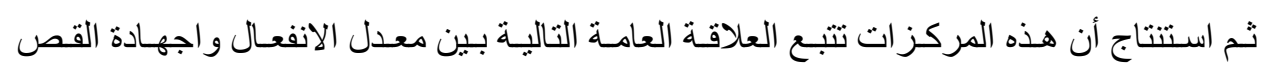
Pseudoplastic Fluid

$$
\tau=\mathrm{K} \gamma \mathrm{n}
$$

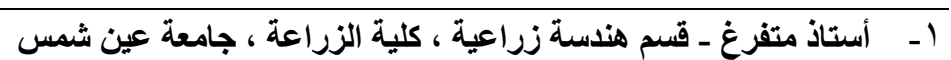

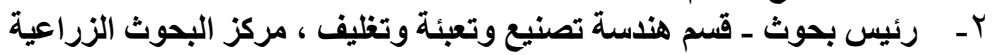

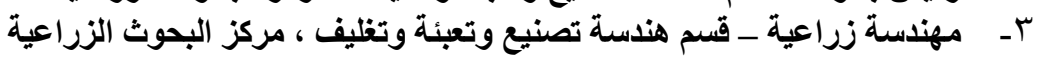

